\title{
Hybrid composite material based on polythiophene derivative nanofibers modified with gold nanoparticles for optoelectronics applications
}

\author{
Rafaela C. Sanfelice ${ }^{1, *}$, Luiza A. Mercante ${ }^{1}$, Adriana Pavinatto ${ }^{1}$, Nathália B. Tomazio ${ }^{2}$, \\ Cleber R. Mendonça ${ }^{2}$, Sidney J. L. Ribeiro ${ }^{3}$, Luiz H. C. Mattoso ${ }^{1}$, and Daniel S. Correa ${ }^{1,4, *}$ \\ ${ }^{1}$ National Laboratory for Nanotechnology in Agribusiness (LNNA), Embrapa Instrumentação, São Carlos, SP 13560-970, Brazil \\ ${ }^{2}$ São Carlos Institute of Physics (IFSC), São Paulo University (USP), Sãocarlos, SP 13560-970, Brazil \\ ${ }^{3}$ Institute of Chemistry, São Paulo State University (UNESP), Araraquara, SP 14801-970, Brazil \\ ${ }^{4}$ Center for Exact Sciences and Technology, Federal University of São Carlos (UFSCar), São Carlos, SP 13565-905, Brazil
}

Received: 3 August 2016

Accepted: 4 October 2016

Published online:

20 October 2016

(C) Springer Science+Business

Media New York 2016

\begin{abstract}
Conjugated polymers have been extensively applied as active materials in nanostructured platforms for optical and electrical devices. The incorporation of metal nanoparticles (NPs) into the polymer-based platform arises as a strategy to develop novel hybrid functional nanocomposites with enhanced electrical and optical properties. However, efficient and simple processing routes to produce such nanocomposites are still on demand. In this work, we present an effective route to obtain functional nanocomposites based on electrospun nanofibers coated with gold nanoparticles, displaying interesting optical and electrical properties. Polymethyl methacrylate (PMMA) electrospun nanofibers doped with poly(3hexyl thiophene-2,5-diyl) (P3HT) were obtained by the electrospinning technique, and displayed a strong red emission centered at $650 \mathrm{~nm}$ assigned to P3HT. Such nanofibers were deposited on to fluorine-doped tin oxide electrodes and with modified with gold nanoparticles (AuNPs) in order to produce hybrid composite materials. The performance of electrodes modified with PMMA/P3HT-AuNPs composite material was evaluated by impedance spectroscopy and revealed an enhancement of electron transfer kinetics, which indicates it as a potential platform for optical and electrochemical (bio)sensors.
\end{abstract}

\section{Introduction}

The development of novel polymer materials using special monomers (homopolymers and copolymers) or the combination of different polymers (blends), associated techniques that allow the processing of these materials in the micro- or nanoscale are highly pursued. Such materials can reach final optical and electrical properties highly suitable for technological applications [1-13]. In this context, the

Address correspondence to E-mail: rafasanfelice@hotmail.com; daniel.correa@embrapa.br 
electrospinning technique has great potential since it allows the fabrication of polymeric micro- and nanofibers with controlled diameter and morphology [14-18]. The electrospinning method was first proposed by Formhals in 1956 [19], but only years later was rediscovered by Reneker and Doshi [20] and then widely employed [21]. In terms of applications for optical and chemical sensors, the miniaturization of sensitive material confers improved properties, due to the increased contact surface area with the analyte under investigation [22-31].

Conjugated polymers are employed in several research and technological areas, especially in studies involving sensory platforms [15, 17, 32-38], due to their fascinating optical, electrical, and electrochemical properties. Such properties allow their use in chemical sensing, converting physical and chemical information into qualitative and quantitative signals $[39,40]$. The deposition of polymeric thin films over sensor platforms is a great promise for attaining more sensitive and selective sensors $[26,33,41]$ due to their high surface area-to-volume ratio [17, 42-44]. Besides, the incorporation of some metallic nanoparticles into the polymeric nanostructures brings additional advantages to sensor applications, since these nanoparticles enhance the optical and electrochemical properties via surface plasmon resonance effect and may also confer biocompatibility to the platform [43]. Among metal nanoparticles, gold nanoparticles (AuNPs) are more frequently used because they are chemically stable and can be obtained and customized with different shapes and sizes under ambient pressure.

Although previous investigations reported in the literature describe the fabrication of hybrid materials based on the combination of P3HT and AuNP for applications in transistors, usually a high concentration of P3HT [27, 45] is employed for attaining suitable electrical properties. Here, we report an effective route to obtain electrospun PMMA/P3HT nanofibers coated with gold nanoparticles which combines the interesting electrical and optical properties from AuNPs and P3HT in the same platform, even when small concentrations of P3HT (2\%) are employed. The optical properties of PMMA/P3HT composites nanofibers were investigated by UV-Vis absorption and PL spectroscopy, while Electrochemical Impedance Spectroscopy (EIS) confirmed the enhancement of charge transference efficiency of the PMMA/ P3HT-AuNPs nanofibers.

\section{Experimental}

\section{Materials}

Poly(methylmethacrylate) (PMMA, Mw 350,000 $\mathrm{g} \mathrm{mol}^{-1}$ ), poly(3-hexyl thiophene-2,5-diyl) (P3HT, average $\mathrm{Mn} 15,000-45,000 \mathrm{~g} \mathrm{~mol}^{-1}$ ), and the surfactant hexadecyltrimethylammonium bromide (CTAB) were purchased from Sigma-Aldrich. Chloroform was purchased from Synth Chemical (São Paulo, Brazil). All the chemicals were used as received.

\section{Electrospinning of PMMA/P3HT nanofibers}

The sample preparation conditions of net PMMA nanofibers were optimized in a previous investigations of our group [46]. Initially, PMMA/P3HT solutions using chloroform as solvent were prepared by dissolving $5 \%$ of PMMA ( $\mathrm{w} / \mathrm{v}$ in respect to the solvent), $10 \%$ of CTAB ( $w / w$ in respect to PMMA), and $0.1,0.5,1$, and $2 \%$ of P3HT ( $w / w$ in respect to PMMA), yielding the samples named PMMA/P3HT0.1\%, PMMA/P3HT0.5 \%, PMMA/P3HT1 \%, and PMMA/ P3HT2 \%, respectively. The solutions were stirred for $2 \mathrm{~h}$ at room temperature. The PMMA/P3HT electrospun nanofibers were obtained using an electrospinning apparatus using a feed rate of $0.15 \mathrm{~mL} \mathrm{~h}^{-1}$, an electric voltage of $20 \mathrm{kV}$, a steel needle with inner diameter of $1.2 \mathrm{~mm}$, and a working distance (between the syringe and the metallic collector) of $6 \mathrm{~cm}$.

The nanofibers were electrospun directly onto glass and fluorine-doped tin oxide (FTO) glass substrates to obtain modified electrodes for electrochemical measurements respectively. The substrates were attached to the metallic collector at the same position in all experiments with an optimal deposition time of $30 \mathrm{~min}$.

\section{Adsorption of gold nanoparticles onto the PMMA/P3HT nanofibers}

Gold nanoparticles (AuNPs), synthesized by Turkvich method [47], were used to modify the electrospun nanofibers surface. The electrospun nanofibers deposited onto FTO were immersed into the gold nanoparticles solution, rinsed with distilled water, and dried under ambient conditions. Different adsorption times were tested (10 $\mathrm{min}, 1,5,12$, and $24 \mathrm{~h})$ to attain the best electrochemical properties of the fabricated platforms. The experimental results, 
revealed by impedance spectroscopy, yielded $12 \mathrm{~h}$ as the optimized time.

\section{Nanofibers characterization}

The morphology and size of the nanofibers were evaluated by a scanning electron microscopy (SEM) (JEOL JSM-6510) operating at $10 \mathrm{kV}$, coupled to EDS (energy dispersive $\mathrm{X}$-ray spectroscopy) module. The fiber diameter was estimated using Image J (National Institutes of Health, USA) analysis software. The average nanofiber diameter and distribution were determined by measuring 100 random fibers using representative micrographs.

For FTIR measurements, the electrospun nanofibers were removed from the substrate and placed directly in the FTIR equipment chamber (Bruker Vertex 70). The spectra were collected in ATR mode from 400 to $4000 \mathrm{~cm}^{-1}$ with a resolution of $2 \mathrm{~cm}^{-1}$ (a total of 64 scans were collected for each sample).

UV-Vis absorption spectrum of nanofibers deposited on quartz slides were recorded in reflecting mode using a Varian Cary 5000 spectrometer.

Fluorescence microscopy images of the PMMA/ P3HT nanofibers were obtained using a Carl ZeissLSM510 confocal laser scanning microscope, with excitation centered at $550 \mathrm{~nm}$. The photoluminescence spectrum was collected using a Shimadzu RFPC3501 spectrophotometer. For all cases, the nanofibers were electrospun on glass substrates.

The morphology of nanofibers surface coated with gold nanoparticles was investigated using a field emission gun scanning electron microscope (FEGSEM, JEOL-JSM 6701F).

TGA experiments were performed using a thermogravimetric analyser (Q500 TA Instruments) under nitrogen atmosphere, at a flow rate of $50 \mathrm{~mL} \mathrm{~min}^{-1}$. Samples in platinum pans were scanned from room temperature up to $600{ }^{\circ} \mathrm{C}$ at a heating rate of $10^{\circ} \mathrm{C}$ $\mathrm{min}^{-1}$. DSC analyses were obtained using a Q100 TA calorimetric analyzer under $\mathrm{N}_{2}$ atmosphere at a flow rate of $60 \mathrm{~mL} \mathrm{~min}{ }^{-1}$. The temperature range was set from -80 up to $250{ }^{\circ} \mathrm{C}$ using a scanning rate of $10{ }^{\circ} \mathrm{C} \mathrm{min}{ }^{-1}$. Before the measurements, the nanofibers were dried in vacuum at $60{ }^{\circ} \mathrm{C}$ and placed in an aluminum pan.

\section{Electrochemical measurements}

The electrochemical experiments were performed using a PGSTAT30 Autolab electrochemical system
(Metrohm) controlled with Nova software (1.10). The FTO-PMMA/P3HT-AuNPs electrodes were used as working electrodes. A Pt foil and $\mathrm{Ag} / \mathrm{AgCl}$ (3 $\mathrm{mol} \mathrm{L}^{-1} \mathrm{KCl}$ ) were employed as the counter (CE) and reference (RE) electrodes, respectively. Electrochemical impedance spectroscopy (EIS) measurements were carried out in a $0.05 \mathrm{~mol} \mathrm{~L}^{-1}$ $\left[\mathrm{Fe}(\mathrm{CN})_{6}\right]^{3-/ 4-}$ containing $0.1 \mathrm{~mol} \mathrm{~L}^{-1} \mathrm{KCl}$ at open circuit potential (OCP) over the frequency range from 0.1 to $100 \mathrm{kHz}$, using an amplitude of $10 \mathrm{mV}$. The cyclic voltametry (CV) measurements were performed in sulphuric acid solution $\left(0.1 \mathrm{~mol} \mathrm{~L}^{-1}\right)$ over a potential range from 0.5 to $1.5 \mathrm{~V}$ at a scan rate of $50 \mathrm{mV} \mathrm{s}^{-1}$.

\section{Results and discussion}

\section{PMMA/P3HT nanofibers}

Polythiophene and its derivatives possess interesting optical properties that respond to different stimuli, including color change as a response to variation of molecular conformation. Such color changes, in a similar way to conductivity changes, are induced by the twisting of the conjugated polymer backbone [48]. For this reason, this class of polymer is interesting for application in optical (colorimetric), electrical, and electrochemical sensors. The electrospun nanofibers were fabricated using PMMA as polymeric matrix because of its nanofiber-forming ability useful to produce doped electrospun nanofibers [46], low cost, and high transparency in the UV-Vis region. Fig. 1a$\mathrm{d}$ shows the SEM images of the PMMA/P3HT nanofibers and the size distribution of nanofibers diameters obtained with P3HT concentrations of 0.1, $0.5,1.0$, and $2.0 \%(\mathrm{w} / \mathrm{w})$, respectively. P3HT concentrations higher than $2.0 \%(\mathrm{w} / \mathrm{w})$ tended to induce precipitation in the resulting solution (PMMA/P3HT), which motivated to obtain nanofibers with low amount of P3HT, in contrast to previous works found in literature, which employed higher amounts of P3HT [27, 45]. Other advantages attained by using low amounts of P3HT in the final nanofibers are related to cost (once P3HT is well more expensive than PMMA) and the ease to obtain electrospun nanofibers without surface defects. The mean diameters were obtained by measuring the diameters of 100 random fibers, while the size distribution was fitted using a Gaussian function. The SEM images 

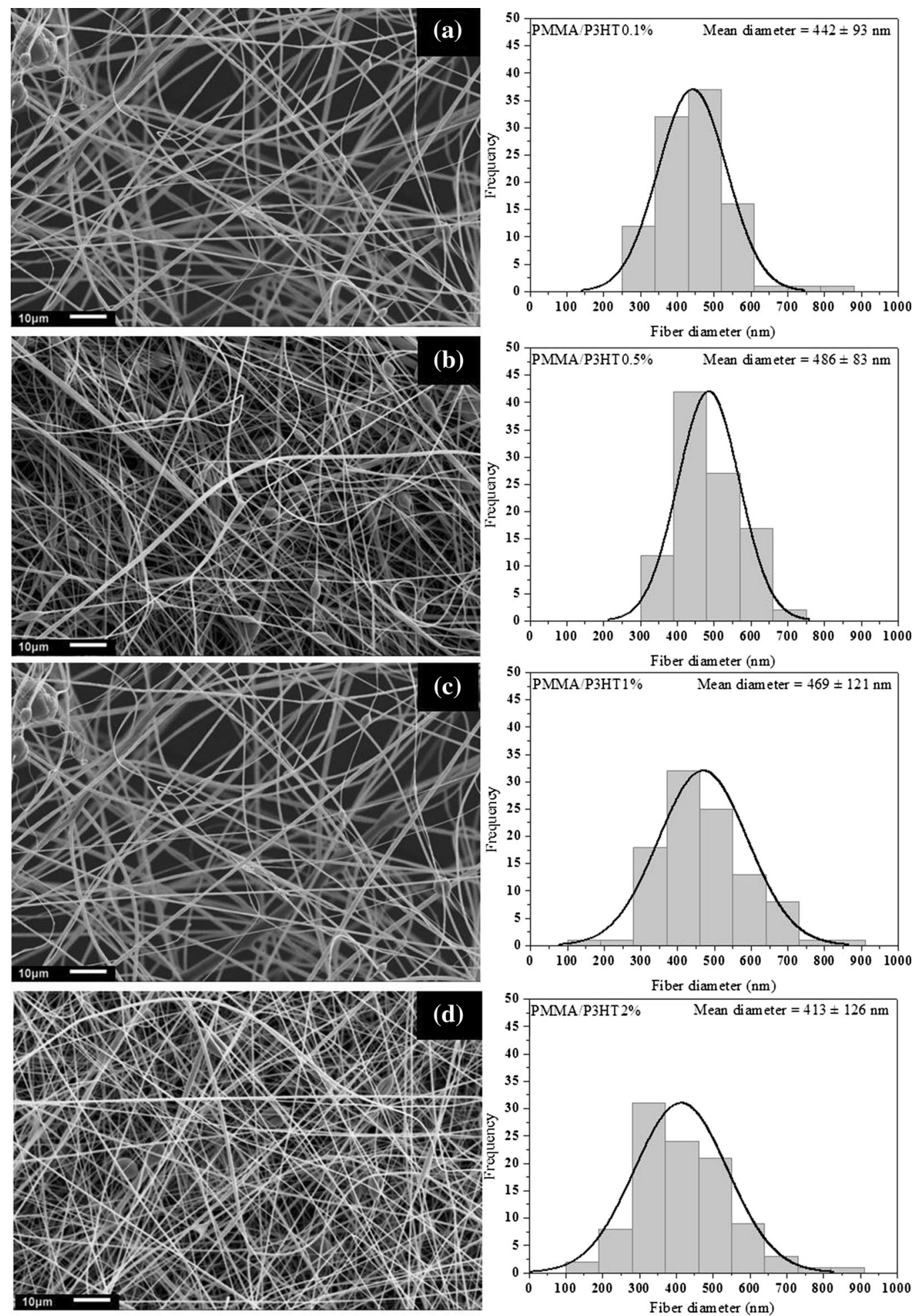

Figure 1 (left) SEM image of PMMA/P3HT nanofibers and (right) the histogram of size distribution using different concentrations of P3HT: a $0.1, \mathbf{b} 0.5$, c 1.0 , and d $2.0 \%(\mathrm{w} / \mathrm{w})$.

reveal smooth and uniform electrospun fiber surfaces, indicating a well-regulated fabrication of PMMA nanofibers doped with P3HT. Although the fiber average diameter varied from $413 \mathrm{~nm}$ up to $486 \mathrm{~nm}$, the differences were not statistically significant considering the deviation. The PMMA/ 


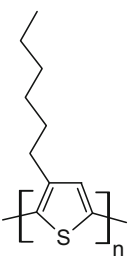

P3HT

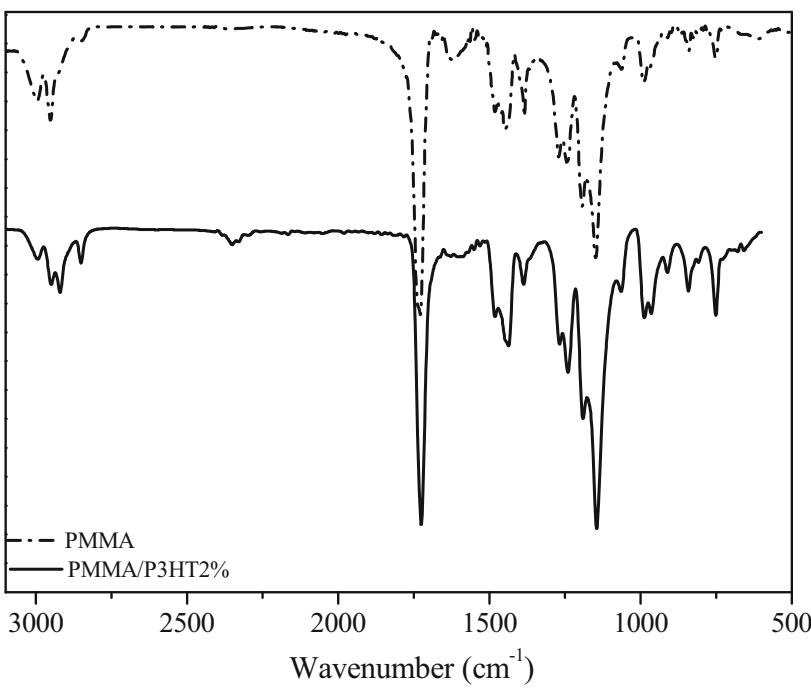

Figure 2 Chemical structures of PMMA and P3HT, and FTIR spectra of PMMA (dashed line) and PMMA/P3HT2 \% (solid line) nanofibers.

P3HT2 \% nanofibers were selected for sequential experiment because of the higher concentration of $\mathrm{P} 3 \mathrm{HT}$, which is desirable for application in sensory platform.

FTIR spectra of PMMA and PMMA/P3HT2 \% are shown in Fig. 2. There is no significant difference between both spectra, since most of the peaks are overlapped, as a consequence of similarities between P3HT and PMMA chemical groups. In addition, the peaks corresponding to the thiophene groups are of low intensity (at $825 \mathrm{~cm}^{-1}$ corresponding to $-\mathrm{C}-\mathrm{H}$ of substituted thiophene ring, $1514 \mathrm{~cm}^{-1}$ corresponding to $-\mathrm{C}=\mathrm{C}$ of thiophene aromatic ring, and $3100 \mathrm{~cm}^{-1}$ corresponding to $\mathrm{C}-\mathrm{H}$ thiophene aromatic ring) due to the low concentration of P3HT contained into the nanofibers. The peaks at $2900 \mathrm{~cm}^{-1}$ are related to axial strain of aliphatic $\mathrm{C}-\mathrm{H}$, at $1729 \mathrm{~cm}^{-1}$ are assigned to axial strain of $\mathrm{C}=\mathrm{O}$, at $1450 \mathrm{~cm}^{-1}$ are associated to angular strain of $\mathrm{CH}_{2}$, at 1270 and $1232 \mathrm{~cm}^{-1}$ are assigned to axial and angular strain of $\mathrm{C}-\mathrm{C}-\mathrm{O}$, and at 1191 and $1144 \mathrm{~cm}^{-1}$ are assigned to axial and angular strain of $\mathrm{C}-\mathrm{O}$.
The PMMA/P3HT2 \% nanofibers deposited on aluminum foil exhibits a homogenous reddish color caused by the P3HT. The optical properties of PMMA/P3HT2 \% nanofibers were also investigated by UV-Vis absorption and PL spectroscopy, as shown in Fig. 3a, b respectively. The PMMA/ P3HT2 \% displays a broad absorption band (black line in Fig. 3a) centered at approximately $510 \mathrm{~nm}$, in which two shoulders can be seen at 430 and $580 \mathrm{~nm}$, as illustrated by the Gaussian decomposition (colored lines in Fig. 3a). These three bands are assigned to the $\pi-\pi^{*}$ transition related to the polymer backbone conjugation.[49].

The electrospun nanofibers displayed a wide emission band (black line in Fig. 3 b), with a peak centered at $630 \mathrm{~nm}$ and two shoulders at 610 and $700 \mathrm{~nm}$, as revealed by the Gaussian decomposition (colored lines in Fig. 3b). The main peak is blueshifted with respect to the values reported previously in the literature for cast films of the same chemical composition [50], once the optical behavior of P3HT in nanofibers is affected by different molecular conformation acquired by the polymer during the electrospinning process [51-54]. Such result is in agreement with the findings reported by Madhugiri et al. [55], in which the blue shift observed for electrospun nanofibers was attributed to the presence of nano-voids within the nanofiber structure. Given that the nanofibers were electrospun from polymer solutions, the rapid solidification of polymer jet during spinning can induce the formation of small air voids within the fiber bulk.

Figure 3c shows a bright field optical microscopy image of PMMA/P3HT2 \% nanofibers, while Fig. 3d displays a fluorescence microscope image of the same nanofibers excited at $550 \mathrm{~nm}$, where a red light uniformly emitted from the nanofibers membrane can be seen. The later results show that P3HT was successfully distributed throughout the PMMA nanofibers and indicate that the P3HT fluorescence was preserved after the electrospinning process. Therefore, the results evidence the optical activity of the PMMA/P3HT2 \% nanofibers and their potential to be applied applications in optical sensors, where the large surface area of the nanofibers can be advantageous for analyte adsorption and fluorescence quenching mechanisms.

Thermal analysis of PMMA and PMMA/P3HT2 \% nanofibers were carried out by TGA and DSC (Fig. 4). TGA curves (Fig. 4a) shows two different thermal 

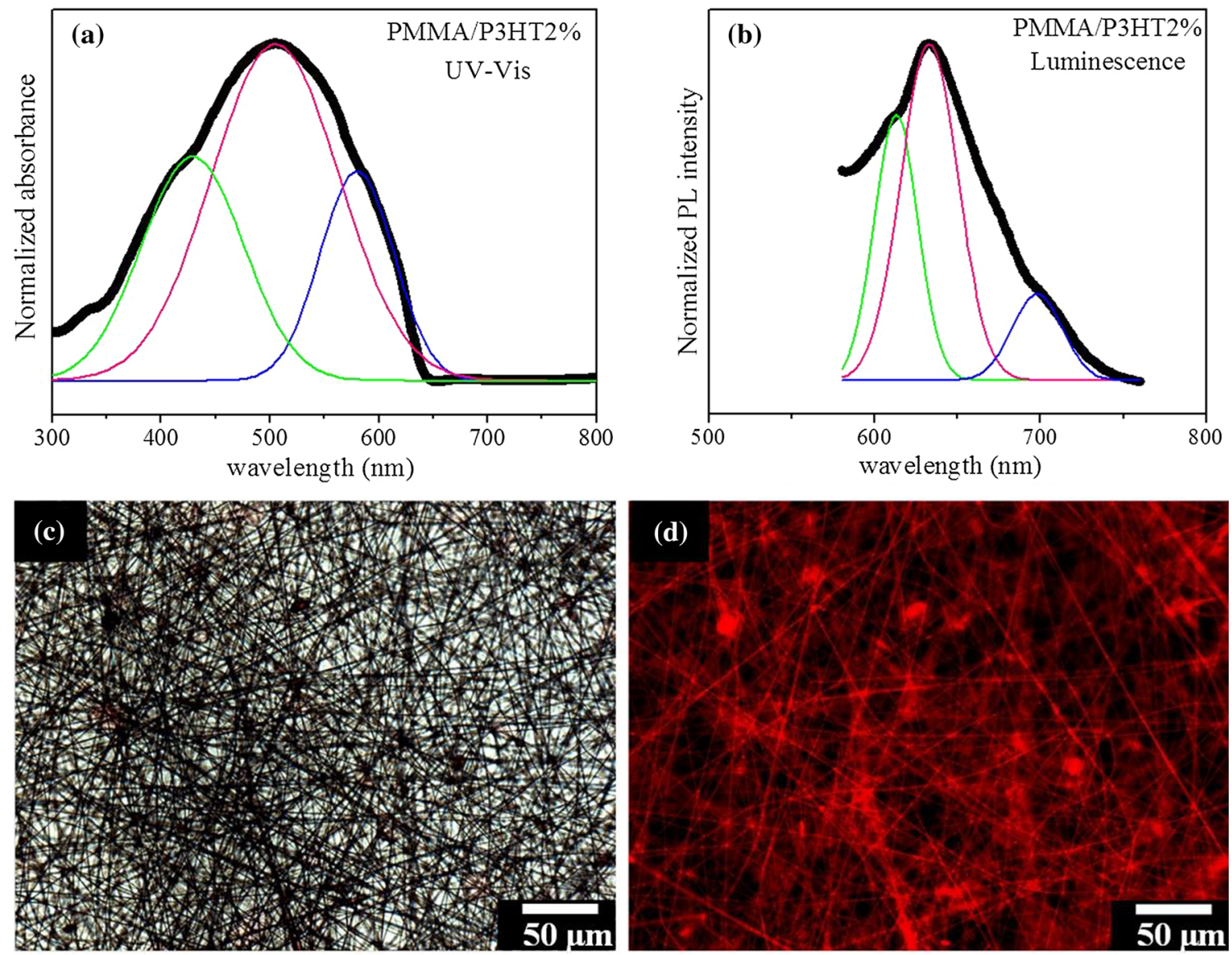

Figure 3 a Normalized absorbance, $\mathbf{b}$ normalized photoluminescence spectrum, $\mathbf{c}$ bright field optical, and $\mathbf{d}$ fluorescence microscopy images of PMMA/P3HT2 \% nanofibers.

events for both PMMA and PMMA/P3HT2 \% curves. The corresponding curve of PMMA nanofibers presents a subtle weight loss in the range from 60 up to $190{ }^{\circ} \mathrm{C}$, which is probably related to the evaporation of residual solvent (chloroform) and low molar mass molecules (such as molecules of CTAB), used to enhance the formation of nanofibers. The second and more pronounced thermal event starting at $250{ }^{\circ} \mathrm{C}$ represents the degradation of PMMA. The same behavior is observed for PMMA/P3HT2 \% nanofibers, with a slight increase of thermal stability.

The DSC curves (Fig. 4b) of PMMA and PMMA/ P3HT2 \% nanofibers were obtained using two methodologies. The first experiment was performed by running the DSC analysis with the nanofibers placed in a closed aluminum pan. In a second experiment, a small puncture was made on the pan, in order to allow the evaporation of residual solvent during the DSC analysis. The DSC curves obtained using closed pans are represented by solid lines, while the curves obtained using punctured pans are represented by dashed line in Fig. 4b. It is possible to observe that the curves of closed pans show two thermal events at 70 and $100{ }^{\circ} \mathrm{C}$, corresponding to chloroform and water evaporation, respectively. Such events probably occurred due to an incomplete solvent evaporation during the electrospinning process, where both chloroform and water molecules remained within the nanofibers bulk. The DSC curves obtained using punctured pan allow the complete evaporation of the solvents, evidencing the glass transition $\left(\mathrm{T}_{\mathrm{g}}\right)$ temperature of PMMA approximately at $110{ }^{\circ} \mathrm{C}$ for net PMMA nanofibers, while for the PMMA/P3HT2 \% nanofibers, a small decrease of $\mathrm{T}_{\mathrm{g}}$ can be observed $\left(105^{\circ} \mathrm{C}\right)$, indicating a good miscibility between PMMA and P3HT.

\section{Incorporation of gold nanoparticles (AuNPs)}

In order to fabricate functional composite materials by electrospinning, the surface of PMMA/P3HT2 \% nanofibers was functionalized with gold 

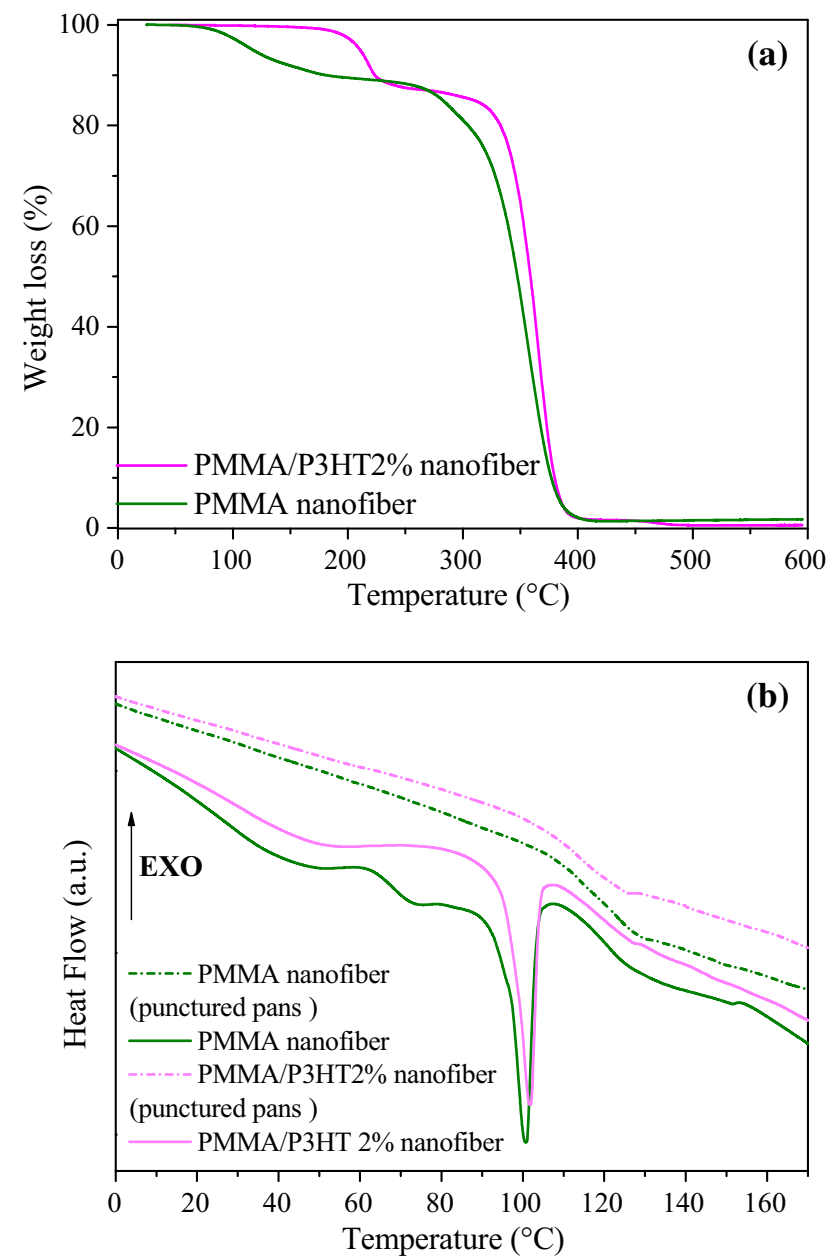

Figure 4 a TGA and $\mathbf{b}$ DSC curves of PMMA and PMMA/ P3HT2 \% nanofibers.

nanoparticles. The composite material was produced by immersing a fiber mat of PMMA/P3HT2 \% in the colloidal gold dispersion $(20 \mathrm{~nm})$ followed by water rinsing and air drying. Through the FEG-SEM image observed in Fig. 5, it is inferred that the AuNPs have good affinity toward the PMMA/P3HT2 \% nanofibers, once they remain adhered on the nanofibers surface. Such affinity is likely due to the hydrogen bonding between $\mathrm{O}-\mathrm{H}$ groups from citrate molecules lying on AuNPs and the $\mathrm{C}=\mathrm{O}$ groups from PMMA [56]. The presence of AuNPs on the surface of nanofiber mats (after immersion during $12 \mathrm{~h}$ in AuNPs solution) was also confirmed by FEG-SEM image.

EDS spectra of PMMA, PMMA/P3HT, and PMMA/P3HT2 \%-AuNPs nanofibers (Fig. 6) were collected and reveal the qualitative chemical composition of each sample. As expected, the peaks

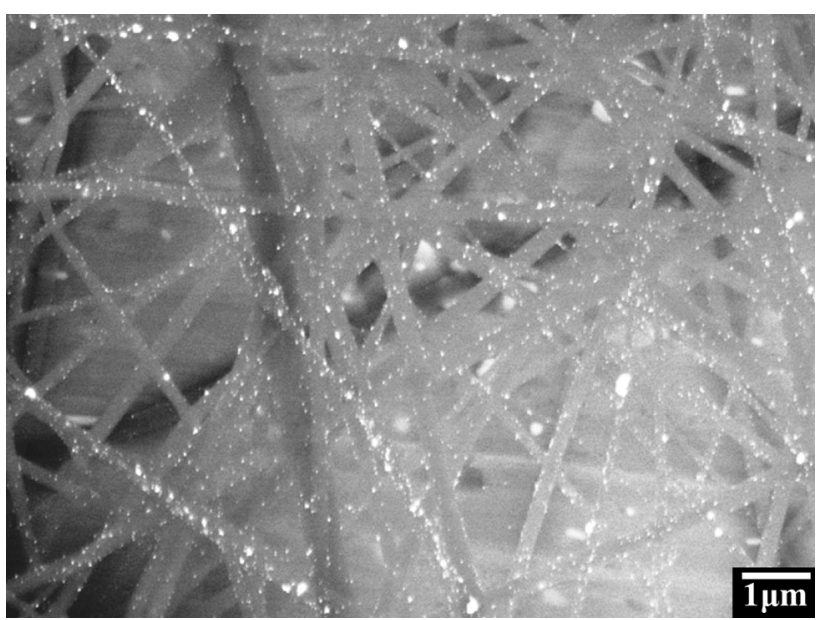

Figure 5 FEG-SEM image of PMMA/P3HT2 \% nanofibers coated with AuNPs.

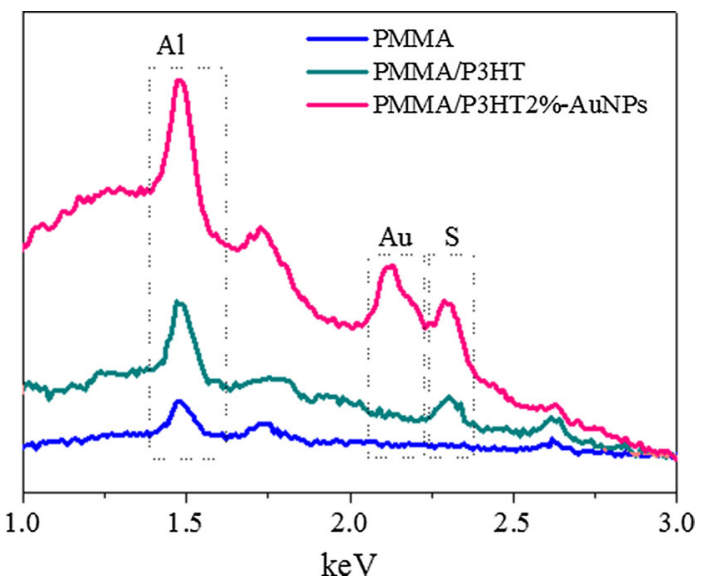

Figure 6 EDS spectra of PMMA, PMMA/P3HT2 \%, and PMMA/P3HT2 \%-AuNPs nanofibers with the peaks corresponding to $\mathrm{Au}$ and $\mathrm{S}$ highlighted.

equivalent to carbon and oxygen were observed in all spectra, whereas the peaks corresponding to the sulphur atoms were observed in nanofibers containing P3HT and P3HT-AuNPs. In the latter sample, it was also possible to observe the peak assigned to the gold atoms. Such results confirm the atomic composition of the fabricated electrospun nanofibers as well as the incorporation of AuNPs onto the PMMA/ P3HT2 \% nanofibers.

The adsorption of AuNPs onto the nanofibers was also proven by cyclic voltammograms measurements of the FTO electrodes modified with PMMA/P3HT2 and PMMA/P3HT2 \%-AuNPs nanofibers in $0.1 \mathrm{~mol} \mathrm{~L}^{-1} \mathrm{H}_{2} \mathrm{SO}_{4}$ at $50 \mathrm{mV} \mathrm{s}^{-1}$, shown in Fig. 7. The nanofiber-modified FTO electrode presents a higher 


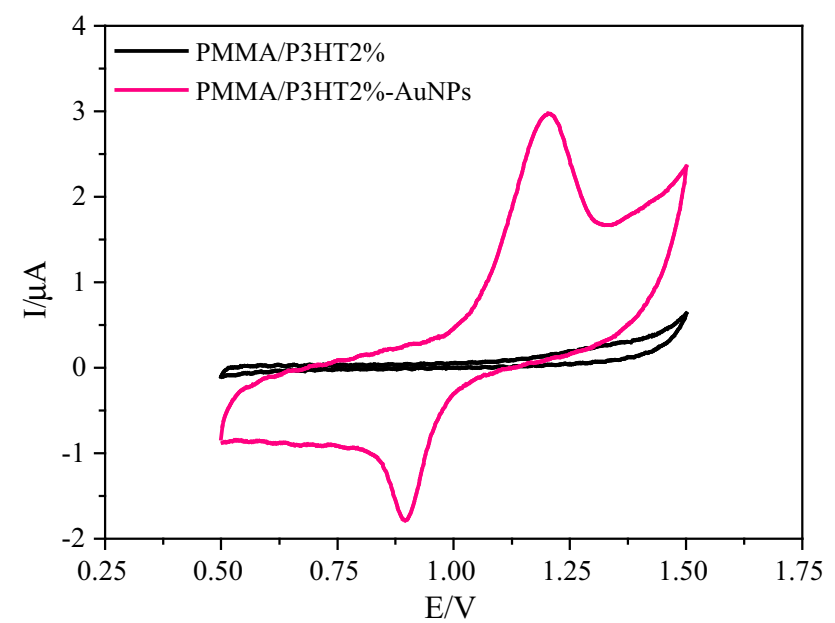

Figure 7 Cyclic voltammetry of FTO electrodes modified with PMMA/P3HT2 \% and PMMA/P3HT2 \%-AuNPs nanofibers in sulphuric acid $0.1 \mathrm{~mol} \mathrm{~L}^{-1}$.

charging current compared to the bare FTO electrode due to an increase of the electrode surface area caused by the nanofibers. No peaks are observed in the cyclic voltammogram of PMMA/P3HT2 \%modified FTO electrode. On the other hand, the PMMA/P3HT2 \%-AuNPs-modified electrode exhibits an anodic current around $1.2 \mathrm{~V}$ assigned to the oxidation of AuNPs deposited onto the nanofibers, and a peak at $0.9 \mathrm{~V}$ attributed to the reduction of the oxide formed on the AuNPs [57, 58]. The oxidation reaction of AuNPs can be described by the following equation:

$2 \mathrm{Au}+3 \mathrm{H}_{2} \mathrm{O} \rightarrow \mathrm{Au}_{2} \mathrm{O}_{3}+6 \mathrm{H}^{+}+6 \mathrm{e}^{-}$.

Impedance spectroscopy (EIS) measurements were carried out in order to evaluate the electron-transfer efficiency in an electrochemical reaction for the proposed nanofiber platforms. The impedance spectroscopy data are represented by the Nyquist diagram shown in Fig. 8, which was analyzed using the Randles equivalent circuit, shown in the inset of Fig. 8. In this figure, $C$ represents the interface capacitance, $R_{\mathrm{s}}$ is the electrolyte resistance, $R_{\mathrm{ct}}$ is the electron charge-transfer resistance, and $W$ is the Warburg impedance. The Nyquist diagram displays two distinct regions: a semicircular region at high frequencies, which is related to a charge-transfer process and a linear region related to interfacial diffusion processes [59]. The diameter of the semicircular region in the Nyquist plots is directly related to the charge-transfer resistance of the material interface. Therefore, the smaller the diameter, the smaller

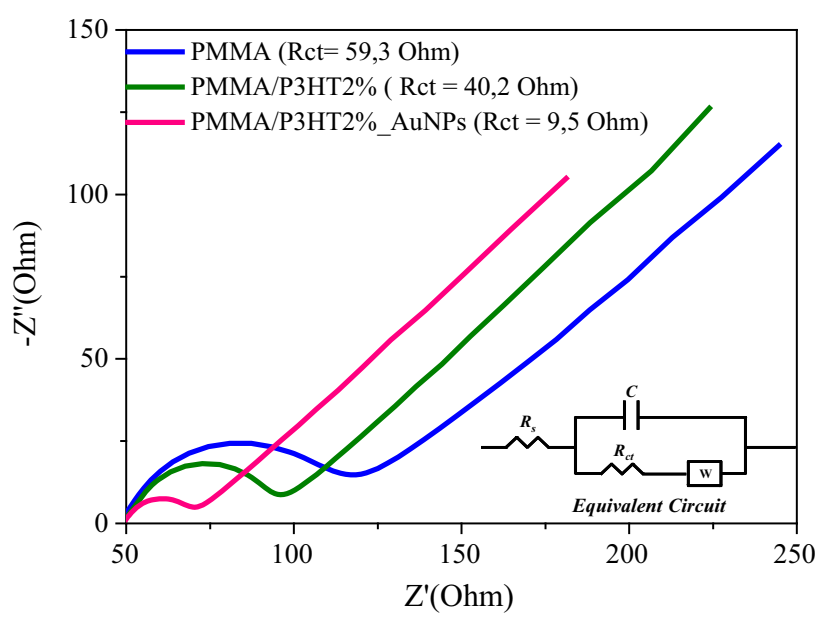

Figure 8 Nyquist plots of EIS in $5 \mathrm{mmol} \mathrm{L}^{-1}\left[\mathrm{Fe}(\mathrm{CN})_{6}\right]^{3-/ 4-}$ solution with $0.1 \mathrm{~mol} \mathrm{~L}^{-1} \mathrm{KCl}$. The inset shows the Randle's equivalent circuit model for the impedance data.

the charge transfer resistance. One notes that the presence of P3HT and AuNPs in the nanofibers decreases the total charge transfer resistance (59, 40, and $9.5 \Omega$ for PMMA, PMMA/P3HT2, and PMMA/ P3HT2 \%-AuNPs, respectively) and consequently increases the electron transfer efficiency. Such effect can be explained by the semiconductor characteristics of the P3HT combined to the high conducting surface area of AuNPs. These results indicate that the PMMA/P3HT2 and PMMA/P3HT2 \%-AuNP nanofibers are interesting for application in electrochemical sensing platform.

\section{Conclusions}

PMMA/P3HT nanofibers were successfully obtained by electrospinning from blend solutions of PMMA containing P3HT in concentrations of $0.1,0.5,1.0$, and $2.0 \%(\mathrm{w} / \mathrm{w})$. The well-regulated fabrication of doped electrospun fiber yielded uniform nanofibers with smooth surfaces and fiber average diameter around $450 \mathrm{~nm}$. The optical properties of PMMA/P3HT2 \% nanofibers were evidenced by PL and UV-Vis absorption spectroscopy and in which three peaks in the visible region $(430,510$, and $580 \mathrm{~nm})$ were identified and related to the $\pi-\pi^{*}$ transition of the P3HT backbone conjugation. The PMMA/P3HT2 \% nanofibers displayed an emission centered at $650 \mathrm{~nm}$ assigned to P3HT, even a when small concentration of the conjugated polymer was employed. The electrochemical properties of PMMA/P3HT2 \% 
nanofibers could be enhanced through the incorporation of gold nanoparticles onto the nanofibers surface. The charge transfer resistance of the material interface was investigated by Nyquist plots and revealed that $\mathrm{P} 3 \mathrm{HT}$ and AuNPs increased the electron transfer because of the semiconducting characteristics of the $\mathrm{P} 3 \mathrm{HT}$ and the high conducting surface of AuNPs. The results show that the platform based on conducting nanofibers of PMMA/P3HT2 \% modified with AuNPs exhibits interesting features to be applied in optical and electrochemical sensors.

\section{Acknowledgements}

This work was financially supported by FAPESP (Grant Numbers: 2014/16789-5, 2012/23880-3, and 2013/26712-7), CNPq (402.287/2013, 303.796/2014-6), MCTI-SisNano, CAPES, and EMBRAPA AgroNano Network.

\section{References}

[1] Nakane K, Morinaga M, Ogata N (2013) Formation of niobium oxide and carbide nanofibers from poly(vinyl alcohol)/niobium oxide composite nanofibers. J Mater Sci 48:7774-7779. doi:10.1007/s10853-013-7614-0

[2] Saleem M, Yu H, Wang L et al (2015) Review on synthesis of ferrocene-based redox polymers and derivatives and their application in glucose sensing. Anal Chim Acta 876:9-25. doi:10.1016/j.aca.2015.01.012

[3] Zellmeier M, Rappich J, Klaus M et al (2015) Side chain engineering of poly-thiophene and its impact on crystalline silicon based hybrid solar cells side chain engineering of poly-thiophene and its impact on crystalline silicon based hybrid solar cells. Appl Phys Lett 107:1-4. doi:10.1063/1. 4935751

[4] Kim S, Lee H, Mun J, Lee S (2016) Marginal solvents preferentially improve the molecular order of thin polythiophene fi lms. RSC Adv 6:23640-23644. doi:10.1039/ C6RA00504G

[5] Massoumi B, Jaymand M (2016) Nanostructured star-shaped polythiophene with tannic acid core: synthesis, characterization, and its physicochemical properties. J Appl Polym Sci 43513:1-11. doi:10.1002/app.43513

[6] Mehmood U, Al-ahmed A, Hussein IA (2016) Review on recent advances in polythiophene based photovoltaic devices. Renew Sustain Energy Rev 57:550-561. doi:10.1016/j. rser.2015.12.177
[7] Sehgal P, Narula A (2015) Quantum dot sensitized solar cell based on poly (3-hexyl thiophene)/CdSe nanocomposites. Opt Mater (Amst) 48:44-50. doi:10.1016/j.optmat.2015.07. 027

[8] Oliveira EF, Lavarda FC (2016) Copolymers with similar comonomers: tuning frontier orbital energies for application in organic solar cells. Polym eng Sci 56:479-487. doi:10. 1002/pen.24275

[9] Huynh TP, Sharma PS, Sosnowska M et al (2015) Functionalized polythiophenes: recognition materials for chemosensors and biosensors of superior sensitivity, selectivity, and detectability. Prog Polym Sci 47:1-25. doi:10. 1016/j.progpolymsci.2015.04.009

[10] Madani A, Maouche N, Riahi F, Chehimi MM (2015) Onestep generated poly(3-methylthiophene)/CdSe nanocomposite thin films: redox, impedance and enhanced photoelectrochemical properties. Ionics (Kiel) 21:2031-2037. doi:10. 1007/s11581-015-1382-6

[11] Zhang Y, Li P, Xu X et al (2015) $\mathrm{SnO}_{2}$ films: in-situ template-sacri ficial growth and photovoltaic property based on $\mathrm{SnO}_{2}$ /poly (3-hexyl-thiophene) for hybrid solar cell. Mater Res Bull 70:579-583. doi:10.1016/j.materresbull.2015.05. 031

[12] Chevrier M, Kesters J, Blayo C et al (2016) Regioregular polythiophene-porphyrin supramolecular copolymers for optoelectronic applications. Macromol Chem Phys 217:445-458

[13] Li D, Wang J, Dong X et al (2013) Fabrication and luminescence properties of $\mathrm{YF} 3: \mathrm{Eu}^{3+}$ hollow nanofibers via coaxial electrospinning combined with fluorination technique. J Mater Sci 48:5930-5937. doi:10.1007/s10853-0137388-4

[14] Xin Y, Ling Z, Li S et al (2012) Preparation of single conjugated polymer nanofibers with high opto-electric response. Mater Sci Eng B 177:1094-1097. doi:10.1016/j.mseb.2012. 05.010

[15] Hai YZ, Ang DW, Iu HL et al (2015) Electrochemical molecular imprinted sensors based on electrospun nanofiber and determination of ascorbic acid. Nanalitycal Sci 31:793-798

[16] Andre RS, Pavinatto A, Mercante L et al (2015) Improving the electrochemical properties of polyamide 6/polyaniline electrospun nanofibers by surface modification with $\mathrm{ZnO}$ nanoparticles. RSC Adv. doi:10.1039/C5RA15588F

[17] Aussawasathien D, Dong JH, Dai L (2005) Electrospun polymer nanofiber sensors. Synth Met 154:37-40. doi:10. 1016/j.synthmet.2005.07.018

[18] Jagadeesh Babu V, Pavan Kumar VS, Sundaray B et al (2007) Preparation and characterization of electrospun nanofibers of Nylon-6 doped with copper(II) chloride. Mater 
Sci Eng B Solid-State Mater Adv Technol 142:46-50. doi:10.1016/j.mseb.2007.06.007

[19] Formhals A (1956) Artificial fiber construction. Patent. 1-28. doi: 10.1063/1.4811472

[20] Doshi J, Reneker DH (1993) Electrospinning process and applications of electrospun fibers. J Electrostat 35:151-160. doi:10.1109/IAS.1993.299067

[21] Li D, Xia Y (2004) Electrospinning of nanofibers: reinventing the wheel? Adv Mater 16:1151-1170. doi:10.1002/ adma.200400719

[22] Shi X, Zhou W, Ma D et al (2015) Electrospinning of nanofibers and their applications for energy devices. J Nanomater 2015:1-20. doi:10.1155/2015/140716

[23] Subbiah T, Bhat GS, Tock RW et al (2005) Electrospinning of nanofibers. J Appl Polym Sci 96:557-569. doi:10.1002/ app. 21481

[24] Huang ZM, Zhang YZ, Kotaki M, Ramakrishna S (2003) A review on polymer nanofibers by electrospinning and their applications in nanocomposites. Compos Sci Technol 63:2223-2253. doi:10.1016/S0266-3538(03)00178-7

[25] Ramakrishna S, Fujihara K, Teo WE et al (2006) Electrospun nanofibers: solving global issues. Mater Today 9:40-50. doi:10.1016/S1369-7021(06)71389-X

[26] Chen J-Y, Wu H-C, Chiu Y-C et al (2015) Electrospun poly(3-hexylthiophene) nanofibers with highly extended and oriented chains through secondary electric field for highperformance field-effect transistors. Adv Electron Mater 1400028:1-8. doi:10.1002/aelm.201400028

[27] Chang HC, Liu CL, Chen WC (2013) Flexible nonvolatile transistor memory devices based on one-dimensional electrospun P3HT: au hybrid nanofibers. Adv Funct Mater 23:4960-4968. doi:10.1002/adfm.201300283

[28] Thavasi V, Singh G, Ramakrishna S (2008) Electrospun nanofibers in energy and environmental applications. Energy Environ Sci 1:205. doi:10.1039/b809074m

[29] Lin H-J, Chen C-Y (2016) Thermo-responsive electrospun nanofibers doped with 1,10-phenanthroline-based fluorescent sensor for metal ion detection. J Mater Sci 51:1620-1631. doi:10.1007/s10853-015-9485-z

[30] Senthamizhan A, Balusamy B, Uyar T (2015) Glucose sensors based on electrospun nanofibers: a review. Anal Bioanal Chem 408:1285-1306. doi:10.1007/s00216-0159152-x

[31] Oliveira ON Jr, Aoki PH, Pavinatto FJ, Constantino CJ (2012) Controlled architectures in LbL films for sensing and biosensing. In: multilayer thin film. Seq Assem Nanocomposite Mater, 2nd edn. pp 951-984

[32] Wang J-Y, Su Y-L, Wu B-H, Cheng S-H (2016) Reusable electrochemical sensor for bisphenol a based on ionic liquid functionalized conducting polymer platform. Talanta 147:103-110. doi:10.1016/j.talanta.2015.09.035

[33] Li H-H, Wang H-H, Li W-T et al (2016) A novel electrochemical sensor for epinephrine based on three dimensional molecularly imprinted polymer arrays. Sens Actuators B Chem 222:1127-1133. doi:10.1016/j.snb.2015.08.018

[34] Ates M (2013) A review study of (bio)sensor systems based on conducting polymers. Mater Sci Eng, C 33:1853-1859. doi:10.1016/j.msec.2013.01.035

[35] Cordova Mateo E, Poater J, da Cruz Teixeira Dias BJ et al (2014) Electroactive polymers for the detection of morphine. J Polym Res 21:1-13. doi:10.1007/s10965-014-0565-6

[36] Wang X, Kim YG, Drew C et al (2004) Electrostatic assembly of conjugated polymer thin layers on electrospun nanofibrous membranes for biosensors. Nano Lett 4:331-334. doi:10.1021/n1034885z

[37] Sahli R, Raouafi N, Maisonhaute E et al (2012) Thiophenebased electrochemically active probes for selective calcium detection. Electrochim Acta 63:228-231. doi:10.1016/j.elec tacta.2011.12.108

[38] Şenel M, Dervisevic M, Çevik E (2013) A novel amperometric glucose biosensor based on reconstitution of glucose oxidase on thiophene-3-boronic acid polymer layer. Curr Appl Phys 13:1199-1204. doi:10.1016/j.cap.2013.03.004

[39] Bernius MT, Inbasekaran M, O'Brien J, Wu W (2000) Progress with light-emitting polymers. Adv Mater 12:1737-1750. doi:10.1002/1521-4095(200012)12: $23<1737$ :AID-ADMA1737>3.0.CO;2-N

[40] Olivati CA, Gonçalves VC, Balogh DT (2012) Optically anisotropic and photoconducting Langmuir-Blodgett films of neat poly(3-hexylthiophene). Thin Solid Films 520:2208-2210. doi:10.1016/j.tsf.2011.10.032

[41] Chen Y, Xie G, Xie T et al (2015) Thin film transistors based on poly(3-hexylthiophene)/[6,6]-phenyl C61 butyric acid methyl ester hetero-junction for ammonia detection. Chem Phys Lett 638:87-93. doi:10.1016/j.cplett.2015.07.026

[42] Ding B, Kim J, Miyazaki Y, Shiratori S (2004) Electrospun nanofibrous membranes coated quartz crystal microbalance as gas sensor for NH3 detection. Sens Actuators B Chem 101:373-380. doi:10.1016/j.snb.2004.04.008

[43] Correa DS, Medeiros ES, Oliveira JE et al (2014) Nanostructured conjugated polymers in chemical sensors: synthesis, properties and applications. J Nanosci Nanotechnol 14:6509-6527. doi:10.1166/jnn.2014.9362

[44] Sanfelice RC, Gonc VC, Av C et al (2014) Langmuir and Langmuir-Schaefer films of Poly(3-hexylthiophene) with gold nanoparticles and gold nanoparticles capped with 1-Octadecanethiol. J Phys Chem C 118:12944-12951. doi:10.1021/jp503083k 
[45] Niles ET, Roehling JD, Yamagata H et al (2012) J-aggregate behavior in poly-3-hexylthiophene nanofibers. J Phys Chem Lett 3:259-263. doi:10.1021/jz201509h

[46] Roque AP, Mercante LA, Scagion VP et al (2014) Fluorescent PMMA/MEH-PPV electrospun nanofibers: investigation of morphology, solvent, and surfactant effect. J Polym Sci, Part B 52:1388-1394. doi:10.1002/polb.23574

[47] Kimling J, Maier M, Okenve B et al (2006) Turkevich method for gold nanoparticle synthesis revisited. J Phys Chem C 110:15700-15707. doi:10.1021/jp061667w

[48] Perepichka IF, Perepichka DF, Meng H, Wudl F (2005) Light-emitting polythiophenes. Adv Mater 17:2281-2305. doi:10.1002/adma.200500461

[49] Shrotriya V, Ouyang J, Tseng RJ et al (2005) Absorption spectra modification in poly(3-hexylthiophene):methanofullerene blend thin films. Chem Phys Lett 411:138-143. doi:10.1016/j.cplett.2005.06.027

[50] Chan KHK, Yamao T, Kotaki M, Hotta S (2010) Unique structural features and electrical properties of electrospun conjugated polymer poly(3-hexylthiophene) (P3HT) fibers. Synth Met 160:2587-2595. doi:10.1016/j.synthmet.2010.10. 009

[51] Tremel K, Ludwigs S (2014) Morphology of P3HT in thin films in relation to optical and electrical properties. Adv Polym Sci 265:39-82. doi:10.1007/12_2014_288

[52] Böckmann M, Schemme T, de Jong DH et al (2015) Structure of P3HT crystals, thin films, and solutions by UV/Vis spectral analysis. Phys Chem Chem Phys 17:28616-28625. doi: $10.1039 / \mathrm{C} 5 \mathrm{CP} 03665 \mathrm{H}$

[53] Wang C, Duong DT, Vandewal K et al (2015) Optical measurement of doping efficiency in poly(3-hexylthiophene) solutions and thin films. Phys Rev B 91:1-7. doi:10.1103/ PhysRevB.91.085205

[54] Saini V, Li Z, Bourdo S et al (2009) Electrical, optical, and morphological properties of p3ht-mwnt nanocomposites prepared by in situ polymerization. J Phys Chem C 113:8023-8029

[55] Madhugiri S, Dalton A (2003) Electrospun MEH-PPV/SBA15 composite nanofibers using a dual syringe method. J Am Chem Soc 125:14531-14538. doi:10.1021/ja030326i

[56] Dong H, Wang D, Sun G, Hinestroza JP (2008) Assembly of metal nanoparticles on electrospun nylon 6 nanofibers.pdf. Chem Mater 20:6627-6632

[57] Vesali-Naseh M, Mortazavi Y, Khodadadi AA et al (2013) Plasma thiol-functionalized carbon nanotubes decorated with gold nanoparticles for glucose biosensor. Sensors Actuators 188:488-495. doi:10.1016/j.snb.2013.07.022

[58] Su W, Kim S-E, Cho M et al (2013) Selective detection of endotoxin using an impedance aptasensor with electrochemically deposited gold nanoparticles. Innate Immun 19:388-397. doi:10.1177/1753425912465099

[59] Wang Q, Moser J-E, Grätzel M (2005) Electrochemical impedance spectroscopic analysis of dye-sensitized solar cells. J Phys Chem B 109:14945-14953. doi:10.1021/jp052768h 